\title{
Celiac Disease - A Case Series from North India
}

\author{
Lalit Bharadia $^{1} \cdot$ Lalita Kanojiya $^{1} \cdot$ Sanjay Choudhary $^{1} \cdot$ Deepak Shivpuri $^{1}$
}

Received: 28 June 2014 / Accepted: 12 May 2015 / Published online: 26 May 2015

(C) Dr. K C Chaudhuri Foundation 2015

To the Editor: Celiac Disease (CD) is an immunemediated multisystem disorder elicited by gluten in genetically susceptible individuals. It has a prevalence of 0.8 to $2.67 \%$ in the Western world [1]. In India, CD is prevalent in $1.54 \%$ by serology and $1.04 \%$ by histology [2]. There is paucity of data on CD in children from Rajasthan, which happens to be one of the important states of celiac belt of India [3].

We retrospectively analyzed clinical, laboratory and histological features of Celiac disease at a single centre over a $2 \mathrm{y}$ period (Jan 2010-Dec 2011). Two hundred thirty four children with a clinical suspicion of Celiac disease underwent upper gastrointestinal endoscopy and duodenal biopsy in Pediatric Gastroenterology unit. Tissue Transglutaminase IgA (TTG) was done in all (Kit - Aeskulisa; method of test - Serum Enzyme Immunoassay). Gluten free diet (GFD) was prescribed to children with duodenal biopsy histopathology Marsh grade II with serology positive and Marsh grade III. Celiac disease was confirmed among these who had unequivocal clinical improvement on GFD on follow up.

Total 176 children were diagnosed as CD in the study period. The presenting symptoms were chronic diarrhea in 65 (37\%), short stature in $65(37 \%)$, abdominal distension in 33 (19\%), pain abdomen in 13 (7\%) and constipation $9(5 \%)$ children. Anemia was found in $158(90 \%)$ children of which $45(26 \%)$ had severe anemia.

Lalit Bharadia

lalitbharadia@rediffmail.com

1 Centre for Advanced Pediatrics, Fortis Escorts Hospital, Jaipur, Rajasthan 302017, India
TTG was negative in $4(2.27 \%)$ patients of $\mathrm{CD}$, one of which had IgA deficiency. TTG was more than 10 times upper limit of normal in 51 children. Histological findings in CD patients showed villous atrophy (Marsh Grade III) in 169 (96\%) while 7 (4\%) had just crypt hyperplasia (Marsh Grade II).

In this study common symptoms reported in CD were chronic diarrhea, short stature and abdominal distension. Anemia and short stature were more in comparison to Western studies, thereby reflecting delayed diagnosis [4]. However, short stature is less as compared to previous Indian study published a decade ago [5]. There is ongoing need to increase the awareness about the different presentations of the disease so as to enable early diagnosis.

\section{Conflict of Interest None. \\ Source of Funding None.}

\section{References}

1. Fasano A, Berti I, Gerarduzzi T, et al. Prevalence of celiac disease in at-risk and not at-risk groups in the United States: a large multicenter study. Arch Intern Med. 2003;163:286-92.

2. Makharia GK, Verma AK, Amarchand R, et al. Prevalence of celiac disease in the northern part of India: a community based study. J Gastroenterol Hepatol. 2011;26:894-900.

3. Ramakrishna BS. Celiac disease: can we avert the impending epidemic in India? Indian J Med Res. 2011;133:5-8.

4. Stone ML, Bohane TD, Whitten KE, Tobias VH, Day AS. Age related clinical features of childhood celiac disease in Australia. BMC Pediatr. 2005;5:11.

5. Poddar U, Thapa BR, Nain CK, Prasad A, Singh K. Celiac disease in children: are they true cases of Celiac disease? J Pediatr Gastroenterol Nutr. 2002;35:508-12. 